\section{Contributions of entrepreneurial orientation in the use of agile methods in project management}

Entrepreneurial orientation

\author{
Vanessa Mesquita Blas Garcia and Cristina Dai Prá Martens
}

DBA and Master Program in Project Management, Nove de Julho University - UNINOVE, São Paulo, Brazil

Rodrigo Baroni Carvalho

PPGA - Post Graduation in Administration,

Pontificia Universidade Catolica de Minas Gerais, Belo Horizonte, Brazil, and

\author{
Mauro Luiz Martens \\ Production Engineering Department, Polytechnic School, \\ University of São Paulo, São Paulo, Brazil
} Revised 20 March 2020 25 June 2020 Accepted 27 June 2020
Received 12 February 2019

\begin{abstract}
Purpose - This paper aims to analyze the degree of contribution of the entrepreneurial orientation (EO) of organizations in the use of agile methods (AM) in project management.

Design/methodology/approach - A quantitative approach with the application of a survey with project professionals resulted in 206 valid answers. The data were analyzed using structural equation modeling and the method of partial least squares (PLS).

Findings - The results present empirical evidence of the significant contribution of $\mathrm{EO}$ in the use of AM in project management, confirming the main hypothesis of this study. This effect was not influenced by the control variables tested.

Research limitations/implications - This study contributes to the development of research on AM and minimizes the literature gap on the connection between entrepreneurship and AM. The results are limited to the sample. Studies with broader samples and different segments are suggested, as well as the contribution of each dimension of the $\mathrm{EO}$ to $\mathrm{AM}$.
\end{abstract}

Practical implications - Innovativeness, risk-taking, proactiveness, autonomy and competitive aggressiveness (EO dimensions) can contribute to the use of $\mathrm{AM}$ and guide actions to develop these behaviors, pursuing better adherence to agile values and the use of AM in project management.

Originality/value - The originality of this study regarding the connection between EO and AM lies on the presentation of a theoretical model of this relationship and reduces the gap in this research field. Given the

(C) Vanessa Mesquita Blas Garcia, Cristina Dai Prá Martens, Rodrigo Baroni Carvalho and Mauro Luiz Martens. Published in Innovation and Management Review. Published by Emerald Publishing Limited. This article is published under the Creative Commons Attribution (CC BY 4.0) licence. Anyone may reproduce, distribute, translate and create derivative works of this article (for both commercial and non-commercial purposes), subject to full attribution to the original publication and authors. The full terms of this licence may be seen at http://creativecommons.org/ licences/by/4.0/legalcode

This research had financial support from Brazilian institutions: $\mathrm{CNPq}$ - National Council for Scientific and Technological Development and FAP-UNINOVE. In addition, the authors would like to thank the reviewers and the editors for the helpful and constructive comments that greatly contributed to improving the final version of this paper. 
INMR

18,1

degree of EO contribution in AM (19.7\%), there are other factors that affect the use of AM in project management that should be investigated.

Keywords Entrepreneurial orientation, Project management, Agile methods, SCRUM

Paper type Research paper

\section{8}

\section{Introduction}

One of the factors for the successful implementation of the agile methodology (AM) is related to the company's culture and the impact on the project team, as it is necessary to prepare the team for its implementation (Rasnacis \& Berzisa, 2017). Characteristics such as entrepreneurial culture, self-managed teams and autonomy in decision-making are considered important for the adoption of AM (Conforto, Salum, Amaral, Silva, \& Almeida, 2014), which refers to the concept of entrepreneurship at the organizational level. When a company has an inclination toward entrepreneurship, it can be said that it has an entrepreneurial orientation (EO) (Covin \& Lumpkin, 2011), and this degree of entrepreneurship may vary owing to the nature of the environment (Kuratko, Morris, \& Schindehutte, 2015). The organization's strategic posture in terms of innovativeness, risk taking, proactiveness, competitive aggressiveness and autonomy is presented in entrepreneurship literature as dimensions of EO (Lumpkin \& Dess, 1996; Jones \& Coviello, 2005; Martens, Machado, Martens, Silva, \& Freitas, 2018).

Based on the aforementioned concepts, it is perceived that the literature on agile methods points out important characteristics for their context that converge with aspects of entrepreneurship. However, there is a lack of studies that investigate the relationship between these themes. Some authors indicate the need for studies considering the environment where agile systems develop, methods and entrepreneurship (Conforto et al., 2014; Conforto, Amaral, Silva, Di Felippo, \& Kamikawachi, 2016; Tolfo, Wazlawick, Ferreira, \& Forcellini, 2018). One of the possibilities recently indicated is related to the incorporation of theories of entrepreneurship to improve research on agile development and reveal the relationships between the practice of entrepreneurship and the practice of agile development (Tolfo et al., 2018).

In this context, our study brings the following research question:

$R Q 1$. To what degree does the organization's EO contribute to the use of agile methods in project management?

It is assumed that an EO characterized by the tendency to innovate, by the behavior of taking risks, by proactive actions, with autonomous teams and individuals, and with competitive aggressiveness behavior can contribute positively to the use of AM. Thus, the objective of this article is to analyze the degree of contribution of the $\mathrm{EO}$ of organizations in the use of agile methods.

To this end, a survey was carried out with professionals who work on projects with AM in companies located in Brazil, resulting in a sample of 206 valid responses. The results demonstrate that there is a significant contribution from the EO for the use of AM, thus confirming the study's hypotheses.

This paper calls into sheds new light on the approximation between EO and AM, confirming the signs in the literature that there are common characteristics between them. In terms of managerial contributions, the results suggest that $\mathrm{EO}$, characterized by innovative behaviors, risk-taking, proactiveness, autonomy and competitive aggressiveness, contributes positively to the use of AM in project management, characterized by some agile values (Beck et al., 2001): individuals and interactions over processes and tools, working software over comprehensive documentation, customer collaboration over contract 
negotiation and responding to change over following a plan. This can serve as a managerial recommendation to managers who intend to implement AM or improve their use.

\section{Literature review}

\subsection{Agile project management methodologies}

Project management is the set of methods or best practices to be used in a project (Špundak, 2014), with the aim of completing the project within the planned timeframe and budget (Liu \& Horowitz, 1989; Hass, 2007). The AM of project management are oriented toward flexibility with the objective of focusing on the product (Rivas \& Godoy de Souza, 2014). In organizations that adopt AM, the strategies foster collaboration, partnerships, iterative deliveries and frequent communication, resulting in the adjustment of projects to the evolution of the market (Floricel, Michela, \& Piperca, 2016). The project manager ceases to exercise the traditional role as a planner and controller but assumes the role of facilitator to direct and coordinate the collaborative efforts of team members, ensuring that the contributions of the participants are reflected in the final decision (Nerur, Mahapatra, \& Mangalaraj, 2005).

The agile manifesto (Beck et al., 2001) presents the four agile values that guide a greater appreciation of individuals and interactions over processes and tools, working software over comprehensive documentation, customer collaboration over contract negotiation and responding to change over following a plan. According to this approach, even if there is value in processes and tools, for example, individuals and interactions should be valued even more.

Scientific studies on AM, although increasing, still lack of further research, both conceptual and empirical, as agile measurement models and their data are still being scientifically validated (Gren, Torkar, \& Feldt, 2017; Gren, Torkar, \& Feldt, 2015; Leppänen, 2013). Studies show different ways of analyzing AM in organizations. Scrum has been identified as the most successful AM, and therefore, its central practices have been used very frequently (meeting of standup, backlog, sprint/iterations, planning the sprint, retrospective, review/demonstration of sprint, user stories, continuous integration, scrum in scrums and pair programming) (Vallon, da Silva Estacio, Prikladnicki, \& Grechenig, 2018).

Although agile or agile maturity levels are very difficult to assess, Gren, Torkar, and Feldt (2017) state that the group's maturity is one of the dimensions of agility. For these authors, the greatest correlations between agility and group development correspond to teamwork, open communication and agile planning. Sheffield and Lemétayer (2013) carried out a factor analysis of the agility indicators in software development, measuring this agility through the four values listed in the agile manifesto and an additional item based on the flexibility of the software development life cycle.

Thus, considering the lack of standardization in the way of analyzing AM, but having as its guide the agile manifesto that states that agile development should focus on the four values (Dybå \& Dingsøyr, 2008; Sheffield \& Lemétayer, 2013; Gren et al., 2015; Beck et al., 2001) and the fact that they are the guidelines for any frameworks or methodologies; for this study, it was decided to adopt the four agile values as a way of analyzing AM in organizations.

\subsection{Entrepreneurial orientation: entrepreneurship at the organizational level}

EO represents the entrepreneurial posture of the organization in its decisions and actions and, therefore, reflects the strategic mentality (Meskendahl, 2010). EO can be conceptualized as the management of the entrepreneurial process, seen in methods, practices and styles of management or decision-making according to the entrepreneurial posture (Freitas, Martens, Boissin, \& Behr, 2012). Some authors claim that EO can positively influence the performance of an organization, based on the fact that organizations with a higher EO tend to be more 
INMR

18,1

successful than organizations with a lower EO (Rauch, Wiklund, Lumpkin, \& Frese, 2009; Oblog, Oblog, \& Pratt, 2010; Covin \& Lumpkin, 2011; Santos \& Marinho, 2018).

Lumpkin and Dess (1996) present important factors to characterize and distinguish entrepreneurial processes, that is, five dimensions of EO: innovativeness, risk taking, proactiveness, competitive aggressiveness and autonomy. In brief, innovativeness reflects the trend for a company to participate and support new ideas, novelty, experimentation and creative processes that can result in new products, services or technological processes (Martens, Freitas, Boissin, \& Behr, 2011). Risk taking reflects risky behavior, affecting a person's likelihood of behaving in a more or less risky manner (Lumpkin \& Dess, 1996). The proactiveness, in turn, is a prospect of seeking opportunities that involves the introduction of new products or services ahead of the competition, anticipating the need to create change and shape the environment (Lumpkin \& Dess, 2001). Competitive aggressiveness reflects the intensity of a company's efforts to overcome rivals, characterized by a combative stance and a resistant response to competitor's actions (Lumpkin \& Dess, 2001). Finally, the autonomy dimension can be considered as the freedom allowed, within organizations, to individuals and teams that can exercise their creativity and ideas necessary for entrepreneurship to occur (Lumpkin \& Dess, 1996).

Considering that the dimensions of $\mathrm{EO}$ are consolidated in literature and have supported the development of several studies (Covin \& Lumpkin, 2011; Martens et al., 2016, 2018), the five dimensions were adopted for the development of this study. Next, the two main pillars of this study, AM and EO, are theoretically related.

\subsection{Research model and hypotheses}

The relationship between EO and AM seems to be evidenced in several AM characteristics, among which anticipation (or proactiveness), decentralization (or autonomy), flexibility (or innovativeness), uncertainties (or risks) stand out because the experiences of team members with similar previous projects allow the team to assume an appropriate strategy when an unexpected change occurs (Li, Yang, Klein, \& Chen, 2011). Agile methods are best performed in organizations that promote a collaboration-oriented culture, with experienced team members interacting with less experienced colleagues (Surendra \& Nazir, 2018). For the success of a project with AM, a decentralized management model should be considered, aiming at entrepreneurship, flexibility, independence, responsibility and creativity in solving problems (Van Marrewijk, 2007). The main management tools, in this context, are not linked to the traditional control mechanism, but to transparency and freedom for managers and employees to solve problems (Van Marrewijk, 2007). Project managers must be innovative in developing new ideas, enthusiastic and capable of overcoming interference resistance (Van Marrewijk, Clegg, Pitsis, \& Veenswijk, 2008).

Considering the dimensions of $\mathrm{EO}$, autonomy portrays the ability of individuals and teams to solve problems and make decisions during the project, which can help overcome requirements uncertainty ( $\mathrm{Li}$ et al., 2011). AM is characterized by allowing its teams to be autonomous and self-organized so that its members can perceive and respond to changing requirements efficiently without waiting for managerial approval. The risk-taking dimension refers to the uncertainty, complexity and uniqueness of project activities, which increases the chances of probable deviations from plans (Kapsali, 2011). AM deal with uncertainties, possible changes in requirements, the evolution of ongoing needs and decision-making throughout the project period, referring to flexibility in project management (Ben-David, Gelbard, \& Milstein, 2012). In this sense, the greater the team's autonomy, the greater the willingness to take risks through trial and error owing to experimentation (Lee \& Xia, 2010).

Innovativeness portrays the organization's tendency to innovate (Martens et al., 2011). Both the structure and the organizational culture oriented toward innovation can contribute to a 
greater engagement with AM than other types of organizations based on bureaucratic and formal needs (Rivas \& Godoy de Souza, 2014; Nerur et al., 2005). Proactiveness portrays attitudes of anticipation, participation, problem solving and the search for opportunities (Freitas et al., 2012). In AM, the ability to anticipate is reflected in team practices, systemic learning and teamwork, allowing for proactive attitudes (Li et al., 2011). Finally, competitive aggressiveness refers to how to respond to business competition (Freitas et al., 2012). Agile development of software evolves toward agility in project management and helps large organizations to compete with small entrepreneurial companies (Stettina \& Hörz, 2015). The agile manifesto recognizes the importance of a competitive advantage and assumes the need to integrate changing requirements throughout the development process by collaborating with the client in obtaining competitive advantage. Therefore, agile processes take advantage of changes to achieve competitive advantage for the customer (Rivas \& Godoy de Souza, 2014).

Thus, with the argument that EO contributes to the use of AM in project management, the main hypothesis of this study is presented:

H1. EO contributes positively to the use of agile methods in project management.

Some aspects about the organization and the professionals are raised in the literature related to the use of AM. VersionOne (2019), which organizes the Annual State of Agile Report, included the size of the organization in the research questionnaire that gives rise to its annual report, in which the percentage, profiles and benefits of adopting AM are presented (Milašinović \& Bakarčić, 2019). The goal is to provide professionals with insight into agile trends, best practices and lessons learned to help them succeed with their agile transformations. Another point to consider is that, although research has not yet confirmed what the best organizational arrangement for the use of AM is, it is suggested that companies should have organizational characteristics and facilitators similar to companies in the software industry and adaptations can be made to software companies as well as more traditional sectors of the industry (Conforto et al., 2014). Thus, the principles of agile management can be applied in different types of businesses, as long as the original plan can be changed quickly and continuously, with the aim of adding value and offering better results (Carlos, Amaral, \& Caetano, 2018). This refers to the potential interference of some control variables $(\mathrm{CVs})$ related to the organization (size, sector and segment), given by the following hypotheses:

H02. The size of the organization significantly interferes with the use of agile methods in project management.

H03. The sector in which the organization operates significantly interferes with the use of agile methods in project management.

H04. The organization's operating segment significantly interferes with the use of agile methods in project management.

Conforto et al. (2014) indicate factors that facilitate the implementation of AM. Among these, the experience of the project team and the experience of the project manager are considered relevant, referring to the relevance of the professionals. In this sense, one of the important terms in the scrum is a team, formed by only three roles (Mundra, Misra, \& Dhawale, 2013): product owner; scrum master; and development team. All management responsibilities on a project are divided between these roles so that they can quickly adjust the project to better meet their goals (Schwaber, 2004). Based on this, CVs related to project professionals (education, experience with $\mathrm{AM}$ and function in $\mathrm{AM}$ ) are proposed, given by the following hypotheses: 
INMR

18,1

H05. The education of the professionals significantly interferes with the use of agile methods in project management.

H06. The experience of professionals in agile methods significantly interferes with the use of agile methods in project management.

H07. The role of professionals (in the agile methods team) significantly interferes with the use of agile methods in project management.

Figure 1 shows the graphical representation of the study's hypotheses, with the latent variables $\mathrm{EO}$ and $\mathrm{AM}$ and the control variables. In the next sections, the contribution potential of the EO in AM, given by the dimensions of the EO, is explored.

The research method used is presented next.

\section{Research method}

We used in our study a quantitative approach, with an explanatory nature and the application of a survey (Freitas, Oliveira, Saccol, \& Moscarola, 2000). Initially, articles were collected from scientific databases for the composition of the theoretical framework (Alacantara \& Martens, 2019). After the theoretical modeling, a survey was carried out with members of project teams working in companies located in Brazil, which adopted frameworks of AM.

The questionnaire used for the survey consisted of an initial "qualifying" question to verify whether the professional is or was part of a project team that had used an AM, and the questionnaire was continued only in cases where the answer was affirmative. The questionnaire had an initial section to characterize the AM framework used, the organization and the respondent; subsequently, sections with questions about AM and EO using a five-point Likert scale were presented. A code was used in data analysis for each indicator in the questionnaire. Thus, the data collection instrument included 13 indicators of EO and 4 of AM (Table 1). The AM scale was extracted from Sheffield \& Lemétayer (2013), created from the values of the agile manifesto (Beck et al., 2001). The EO scale was based on studies by Covin and Slevin (1989), Lumpkin and Dess (2001), Lumpkin, Cogliser, and Schneider (2009), as well as by Martens et al. (2018), who applied it to professionals working with projects.

The AM construct underwent the validation process by using SmartPLS to treat the survey data. Considering that AM, with the four indicators "agile values," is widely used

Figure 1. Graphical representation of the study hypotheses

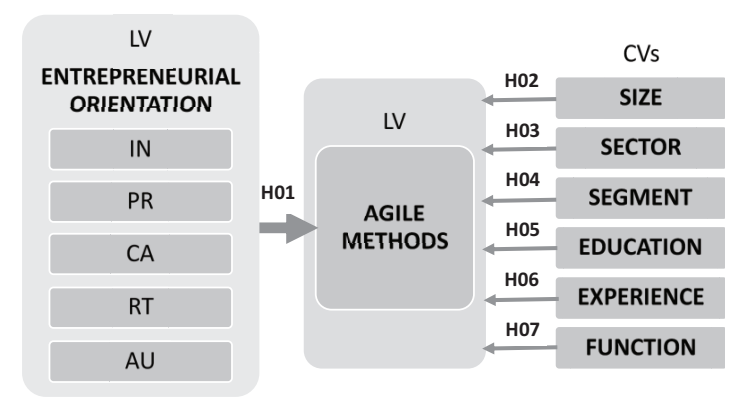

Source: Authors 


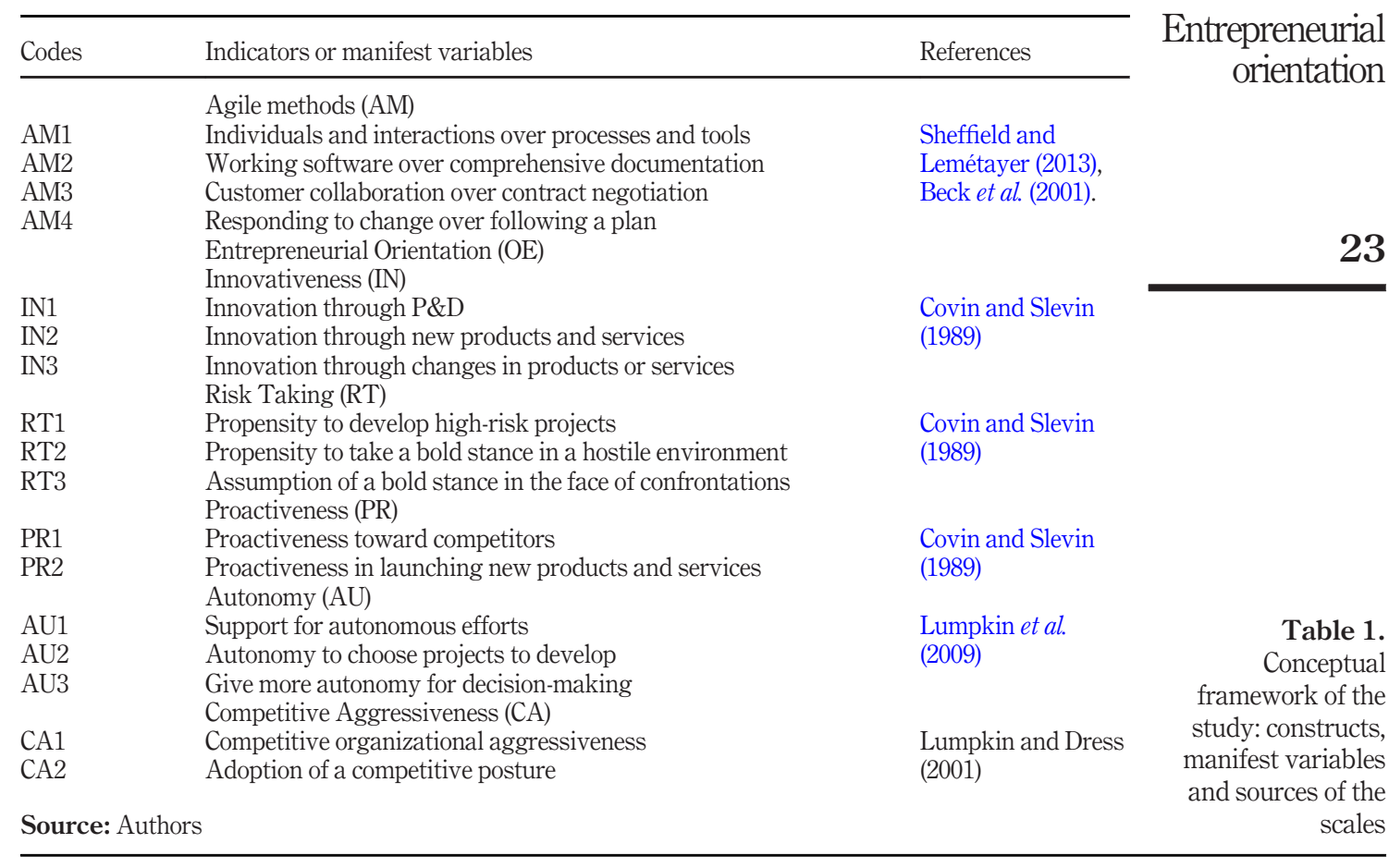

and disseminated by the Manifesto for Agile Software Development (Beck et al., 2001), the process of validating the construct proceeded from the research data. For this, the data were treated by Smart PLS, considering the composite reliability indicators (CR) suitable for the sample analyzed. The data show CR $>0.70$ (Hair, Hult, Ringle, \& Sarstedt, 2014) for three of the four indicators, confirming the permanence of the variables AM1, AM3 and AM4 in the construct AM and in the model. For the variable AM2, the value of 0.591 presented for the external load falls within the parameters $0.40 \leq \mathrm{CR} \leq 0.70$, which, according to Hair et al. (2014), should not be eliminated, as it still presents reliability. Additionally, it was possible to evaluate the Student's $t$-test, which presented values above 1.96 (Hair et al., 2014; Götz, Liehr-Gobbers, \& Krafft, 2010), which justifies the use of the variable as a component of the construct.

Data collection was performed electronically, using the software Sphinx iQ2. The questionnaire link was disseminated through emails, messages in digital applications and sites such as LinkedIn and AM communities, such as the Scrum Alliance. A pretest was carried out with ten participants to identify any errors, which resulted in minor adjustments. To obtain the dimensioning of the sample, the software G*Power v.3.1.9.2 (Faul, Erdfelder, Buchner, \& Lang, 2009), which makes it possible to calculate the minimum sample for the proposed model, was used (Ringle, Da Silva, \& Bido, 2014). For this, the effect size was 0.15 (average value), the power level of the test was 0.95 or $95 \%$, and the maximum allowed error was $5 \%$, as recommended by Cohen (1988). Following these parameters, the minimum sample calculated was 89 questionnaires; however, 206 valid questionnaires were obtained, a number greater than the minimum required and with a test power of $99.98 \%$. 
INMR

18,1

With the return of 206 valid responses, the reliability of the model and valid responses was assessed using Cronbach's alpha (CA), used to analyze whether the sample is free from bias or whether the set of responses is reliable. The values are greater than 0.70 , which is considered satisfactory (Ringle et al., 2014), except for the latent variable IN (0.540). This may represent a bias in the survey responses in the indicators that constitute innovativeness. It can also be explained by the fact that innovativeness is a precondition of the model of AM; however, new research is suggested to equalize this limitation now presented.

The analysis of the collected data was carried out by means of structural equation modeling (SEM), using the method of partial least squares (PLS) (Hair et al., 2014; Ringle et al., 2014), using the SmartPLS 3.0 software (Ringle, Wende, \& Becker, 2015). Thus, in the PLS model proposed for the study, there is the independent variable EO and the dependent variable AM (Byrne, 2010); that is, the EO variable will be a predictor of AM (Bido, Godoy, Araujo, \& Louback, 2010). The latent variable (LV) EO is projected as a second-order reflective (Jarvis, Mackenzie, \& Podsakoff, 2003). In contrast, the tested control variables (size, sector, segment, education, experience, function) were modeled as formative (Jarvis et al., 2003).

\section{Research findings}

\subsection{Sample characterization}

Most respondents have experience in AM, ranging from one to five years (131 respondents or $63 \%$ ), followed by professionals with six to ten years' experience (59 respondents or $29 \%)$. The respondent's positions were: $58(28 \%)$ project manager, $33(16 \%)$ coordinators, 19 (9\%) consultants, $18(8.5 \%)$ managers, 17 (8\%) business analysts, $15(7 \%)$ technical leaders, and the rest occupied other functions. In general, respondents have completed higher education or higher levels: $25 \%$ with completed higher education, $57 \%$ with specialization/ MBA complete or ongoing, $12 \%$ with a masters or doctorate completed or in progress.

Regarding the characterization of organizations, only seven are not Brazilian (Chile, Spain, USA and France). Most companies are in the service sector (78\%); the rest are in trade $(15 \%)$ and industry $(7 \%)$. Most are from the information technology (IT) segment $(65 \%)$, followed by financial $(17 \%)$, in a smaller percentage appear retail, education, health, government, among others. Most are large (55\%) and medium (17\%) companies, followed by small (17\%) and micro companies (11\%).

About the frameworks of AM, $97 \%$ of respondents use Scrum, which corroborates with the study State of Agile Survey (VersionOne, 2019) that points to its predominance. As for the roles that can be developed during the project in AM, among the 199 professionals who work in framework Scrum, it was possible to observe that the majority acted as scrum master (63\%), followed by product owner (24\%), then development team $(13 \%)$.

To characterize the use of AM in organizations, four questions were presented regarding the adherence of projects in relation to agile values. On a scale ranging from 1 (totally disagree) to 5 (totally agree), it is possible to note that most respondents agree on adherence to the AM values. An average result of 3.86 was obtained with a standard deviation of 0.985 for the answers to questions related to AM indicators.

To identify EO in organizations, variables related to the five dimensions of EO were presented: innovativeness, risk taking, proactiveness, autonomy and competitive aggressiveness. The averages of the responses showed a result of 3.29 with an average standard deviation of 1.09 for the responses to the indicators of the dimensions of EO. 
4.2.1 Evaluation of the measurement model. The multivariate statistical analysis of the structural equation modeling (Hair et al., 2009) was carried out using the software SmartPLS 3.0 (Ringle et al., 2014). The treatment of the data followed that recommended by Hair et al. (2014), Henseler, Ringle and Sinkovics (2009) Chin (2010), Götz, Liehr-Gobbers and Krafft (2010), first analyzing the measurement model and, then, the structural model.

Before testing the model, the control variables (CVs) of company size, sector and segment were prepared, as well as education, experience and role of the respondent. They were treated with formative modeling and coded as dummy variables. Thus, in each CV, categories were chosen as a reference, according to the guidance of Falk and Miller (1992). Table 2 shows this categorization and details.

In the measurement model, after the first round of data in the software, the reliability of the model was assessed through internal consistency or reliability of the manifest variables (MVs) or indicators. Following guidelines by Hair et al. (2014) and Henseler, Ringle, and Sinkovics (2009), the standardized loads of the MVs were estimated by projecting values greater than 0.6, with the variable IN03 being excluded. Before excluding IN03, the average variance extracted - average variance extracted (AVE) - for the latent variable (LV) IN was less than the minimum recommended value of 0.5 to indicate convergent validity (Hair et al., 2014; Henseler et al., 2009). Two rounds were performed to achieve the desired internal consistency, with no need to exclude more variables from the model, and with that the latent variable IN reached a satisfactory value of 0.684 of AVE. The AVE greater than 0.5 represents that a LV is able to explain more than half of the variation of its indicators or MVs (Henseler et al., 2009; Hair et al., 2014). Table 3 presents the results of the evaluation of the measurement model.

The next step was to analyze the model's reliability using CA or composite reliability (CR), used to assess whether the sample is free of bias, or whether the set of responses is reliable. The values presented for CR are between 0.70 and 0.90 (Table 3), considered satisfactory (Ringle et al., 2014), except for the latent variable IN, which may represent a bias in the survey responses. However, future studies are suggested to resolve this issue. We then proceeded to the next step, the analysis of the discriminant validity (DV).

The evaluation of the DV of the SEM is an indicator that the constructs or latent variables are independent of each other (Ringle et al., 2014). The first criterion presented

\begin{tabular}{|c|c|c|c|c|}
\hline Control variable (CV) & Category & Number of observations & $(\%)$ & \\
\hline \multirow[t]{2}{*}{ Size } & Large* & 115 & 55.83 & \\
\hline & Medium, small and micro enterprises & 91 & 44.17 & \\
\hline \multirow{2}{*}{ Sector } & Service* & 161 & 78.15 & \\
\hline & Commerce and industry & 45 & 21.84 & \\
\hline \multirow[t]{2}{*}{ Segment } & Information technology (IT)* & 134 & 65.05 & \\
\hline & Others & 72 & 34.95 & \\
\hline \multirow{2}{*}{ Education } & Master and doctorate* & 26 & 12.62 & Table 2. \\
\hline & Up to MBA or specialization & 180 & 87.37 & Categorization of \\
\hline \multirow[t]{2}{*}{ Experience } & Up to five years in $\mathrm{AM}^{*}$ & 131 & 63.59 & CVs by size, sector, \\
\hline & More than five years in AM & 75 & $36: 40$ & segment, education, \\
\hline \multirow[t]{2}{*}{ Function } & Scrum master* & 129 & 62.62 & experience and \\
\hline & Product owner and development team & 77 & 37.37 & function, coded as \\
\hline \multicolumn{4}{|c|}{$\begin{array}{l}\text { Note: *According to Falk and Miller (1992), a category needs to be used as a reference } \\
\text { Source: Research data }\end{array}$} & $\begin{array}{r}\text { formative indicators } \\
\text { dummy }\end{array}$ \\
\hline
\end{tabular}


INMR

18,1

26

refers to the Fornell and Larcker criteria, a requirement met in the analysis (Table 3), in which the square roots of the AVE values of each construct with the Pearson correlations are compared, and the results obtained must be greater than the correlations between the other constructs (Ringle et al., 2014; Fornell \& Larcker, 1981). The second criterion, called cross loads, also indicates the existence of DV, as the square root of the AVE of each variable (Table 4) is greater than the correlations of the other LV (Ringle et al., 2014).

Subsequently, the adjustments of the measurement model were finalized. Subsection 4.2.2 analyzes the structural model.

4.2.2 Evaluation of the structural model. To validate the structural model, Pearson's determination coefficients test $\left(R^{2}\right)$ or explained variance was used initially, which shows the percentage of variance of the dependent LV (AM) that is explained by the independent LV (EO). According to Table 3, all LVs have a $R^{2}$ above 0.26 , classified by Cohen (1988) as indicators of large effect, showing a good fit of the model. Only the dependent variable or endogenous variable had a medium effect, which means that $19.7 \%$ of the effects on the dependent LV AM are explained by the independent LV EO.

Table 3 also shows the values of the fit quality indicator of the model called relevance or predictive validity $\left(\mathrm{Q}^{2}\right)$. This indicator assesses the model's precision (or accuracy). The evaluation criteria are values greater than zero (Ringle et al., 2014). The values obtained by executing the procedure Blindfolding PLS software (Ringle et al., 2014) demonstrate that all dimensions that make up the EO construct presented $\mathrm{Q}^{2}>0$, as well as the AM construct. Therefore, the model has predictive validity or relevance.

\begin{tabular}{lccccccc}
\hline & $\begin{array}{c}\text { Cronbach's } \\
\text { alpha (CA) }\end{array}$ & $\begin{array}{c}\text { Composite } \\
\text { reliability (CR) }\end{array}$ & $\begin{array}{c}\text { Average variance } \\
\text { extracted (AVE) }\end{array}$ & $\begin{array}{c}\mathrm{R}^{2} \\
\mathrm{R}^{2} \\
\text { adjusted }\end{array}$ & $\begin{array}{c}\text { Predictive } \\
\text { validity }{ }^{2}\end{array}$ & $\begin{array}{c}\text { Discriminant } \\
\text { validity (DV) }\end{array}$ \\
\hline CA & 0.736 & 0.883 & 0.790 & 0.560 & 0.558 & 0.426 & 0.753 \\
RT & 0.742 & 0.853 & 0.660 & 0.747 & 0.746 & 0.482 & 0.743 \\
AU & 0.756 & 0.858 & 0.668 & 0.495 & 0.493 & 0.308 & 0.784 \\
IN & 0.540 & 0.812 & 0.684 & 0.441 & 0.438 & 0.292 & 0.544 \\
AM & 0.705 & 0.811 & 0.521 & 0.197 & 0.169 & 0.076 & 0.727 \\
EO & 0.843 & 0.870 & $0.858^{*}$ & - & - & - & 0.871 \\
PR & 0.695 & 0.867 & 0.765 & 0.509 & 0.506 & 0.376 & 0.703
\end{tabular}

Table 3.

Results of the evaluation of the SEM measurement model

Note: *(LV of 2nd order with recalculated AVE); $\left(Q^{2}\right)$ or Stoner-Geisser test; $\left(R^{2}\right)$ Pearson's coefficient Source: Research data extracted from software SmartPLS 3.0 (Ringle et al., 2015)

\begin{tabular}{lccccccc}
\hline & CA & RT & AU & In & AM & EO* & PR \\
\hline CA & 0.889 & - & - & - & - & - & - \\
RT & 0.682 & 0.812 & - & - & - & - & - \\
AU & 0.268 & 0.525 & 0.817 & - & - & - & - \\
IN & 0.403 & 0.435 & 0.390 & 0.827 & - & - & - \\
AM & 0.110 & 0.223 & 0.399 & 0.203 & 0.718 & - & - \\
EO* & 0.748 & 0.864 & 0.704 & 0.664 & 0.431 & $0.926^{*}$ & - \\
PR & 0.551 & 0.524 & 0.300 & 0.463 & 0.136 & 0.713 & 0.875
\end{tabular}

Table 4.

Results of the evaluation of the measurement model by the criterion of the LV correlation matrix
Note: *(LV of second order with recalculated AVE)

Source: Research data extracted from the SmartPLS 3.0 software (Ringle et al., 2015), with special mention for the square root of the value of AVEs - values from each construct 
To assess the level of significance of the structural model, showing the causal relationship between the two constructs, the Student's $t$-test was used (Hair et al., 2014; Götz et al., 2010). Calculations were performed between the original samples of each variable (or each construct) and their samples obtained by using the algorithm option bootstrapping Smart PLS (Ringle et al., 2014). For the structural model to be considered adjusted, it is expected that the result of the values of Student's $t$-test are $p \leq 0.05$ and $t$-values $\geq 1.96$. The results (Table 5) show values of the path coefficients above 1.96 , with a $1 \%$ significance, proving the existence of a causal relationship between the LVs (the independent variable EO in the dependent variable AM) (Hair et al., 2014), as the values are much higher than recommended and identifying the $99 \%$ probability of paths existence. The CVs did not show any interference or significant causal relationship for the use of AM.

Figure 2 shows the final structural model and Table 6 presents the results and the hypothesis test of the structural model, tested using the bootstrapping algorithm (Hair et al., 2014). This analysis showed that the EO construct positively affects the use of AM according to the Student's $t$-test $(4,362$ and with $P$-value $<0.0001)$ and explaining more than $19.7 \%$ of the effects of $\mathrm{EO}$ on the use of AM, confirming the HO1.

For a better visualization of the result of the significance of the path coefficients of the SEM structural model between the LVs and CVs constructs, Figure 2 is presented.

Analyzing the Student's $t$-test for CVs, given by HO2 (company size), HO3 (sector), HO4 (segment), HO5 (education), HO6 (experience) and HO7 (function), it is clear that the results do not prove the existence of significant interference or causal relationship between these $\mathrm{CVs}$ and $\mathrm{AM}$, with a $95 \%$ probability and a $5 \%$ significance, not confirming the hypotheses HO2, HO3, HO4, HO5, HOC and HO7, presenting values of the path coefficients below 1.96 (Hair et al., 2014; Götz et al., 2010).

\section{Discussion of results}

The results of this study present empirical evidence of the significant contribution of EO in the use of AM in project management. This contribution was statistically proven and explained by two tests that confirmed hypothesis $\mathrm{HO1}$ - EO contributes positively to the use of agile methods (AM) in project management.

These results indicate that the organization that has an EO has more adherence to agile values, thus, contributing to the use of AM in project management. This EO is characterized

\begin{tabular}{lcr}
\hline & $t$-test & $p$-value \\
\hline $\mathrm{EO} \rightarrow \mathrm{AM}$ & $4.362^{* * *}$ & $0.000^{*}$ \\
$\mathrm{EO} \rightarrow \mathrm{CA}$ & $18.563^{* * *}$ & $0.000^{*}$ \\
$\mathrm{EO} \rightarrow \mathrm{RT}$ & $38.206^{* *}$ & $0.000^{*}$ \\
$\mathrm{EO} \rightarrow \mathrm{AU}$ & $15.245^{* * *}$ & $0.000^{*}$ \\
$\mathrm{EO} \rightarrow \mathrm{IN}$ & $13.893^{* *}$ & $0.000^{*}$ \\
$\mathrm{EO} \rightarrow \mathrm{PR}$ & $16.427^{* *}$ & $0.000^{*}$ \\
$\mathrm{Size} \rightarrow \mathrm{AM}$ & 0.101 & 0.920 \\
$\mathrm{Sector} \rightarrow \mathrm{AM}$ & 1.193 & 0.233 \\
$\mathrm{Segment} \rightarrow \mathrm{AM}$ & 1.228 & 0.220 \\
Education $\rightarrow$ AM & 0.446 & 0.656 \\
Experience $\rightarrow$ AM & 0.016 & 0.987 \\
Function $\rightarrow$ AM & 0.711 & 0.477
\end{tabular}

Note: *(significant $p$-value); and ${ }^{* *}$ (Student's $t$-test $\left.>1.96\right)$

Source: Research data extracted from the SmartPLS 3.0 software (Ringle et al., 2015)

Entrepreneurial orientation

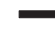




\section{INMR}

18,1

28

Figure 2.

Structured model of the SEM validated

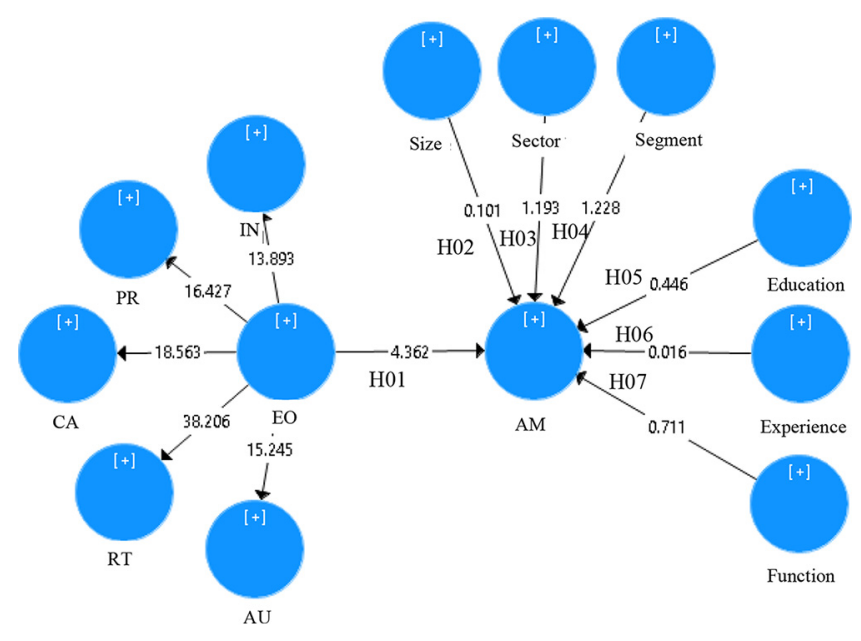

Note: According to Falk and Miller (1992), control variables (CVs) were treated with formative modeling and coded with dummy

Source: Research data extracted from software SmartPLS 3.0 (Ringle et al., 2015)
Table 6.

Results of the evaluation of the SEM structural model and hypothesis testing

\begin{tabular}{|c|c|c|c|c|c|}
\hline $\begin{array}{l}\text { Independent variable } \rightarrow \text { dependent } \\
\text { variable }\end{array}$ & Hypothesis & $\begin{array}{l}\text { Hypothesis } \\
\text { confirmed? }\end{array}$ & $t$-test & $\begin{array}{c}p- \\
\text { value }\end{array}$ & $\begin{array}{c}R^{2} \\
\text { adjusted }\end{array}$ \\
\hline $\mathrm{EO} \rightarrow \mathrm{AM}$ & H01 & Yes & $4.362^{* * *}$ & * $0.000 * 19.7 \%$ & $16.9 \%$ \\
\hline Size $\rightarrow$ AM & H02 & No & 0.101 & $0.920-$ & - \\
\hline Sector $\rightarrow$ AM & H03 & No & 1.193 & 0.233 & \\
\hline Segment $\rightarrow$ AM & H04 & No & 1.228 & 0.220 & \\
\hline Education $\rightarrow$ AM & H05 & No & 0.446 & 0.656 & \\
\hline Experience $\rightarrow$ AM & H06 & No & 0.016 & 0.987 & \\
\hline Function $\rightarrow$ AM & H07 & No & 0.711 & 0.477 & \\
\hline
\end{tabular}

Note: *(significant $p$-value); and **(Student's $t$-test $>1.96$ )

Source: Research data extracted from the SmartPLS 3.0 software (Ringle et al., 2015)

by innovativeness, risk taking, proactiveness, autonomy and competitive aggressiveness. These results corroborate signs in the literature about characteristics of the context of agile methods, such as self-managed teams (Conforto et al., 2014), collaboration-oriented culture (Surendra \& Nazir, 2018), anticipatory behavior (Li et al., 2011), decentralization and flexibility (Ben-David, Gelbard, \& Milstein, 2012), willingness to manage risks (Lee \& Xia, 2010), deal with uncertainties (Li et al., 2011), freedom to manage and solve problems (Van Marrewijk, 2007) and innovative behavior (Van Marrewijk et al., 2008).

Agile development in projects has evolved toward agility in project management, with a need for a quick, more effective and integrated learning process with the entrepreneurial spirit in its operations (Stettina \& Hörz, 2015). In this context, innovativeness can assist in the search for new alternatives and solutions, aligned with risk engagement (risk-taking dimension). Risks are inherent 
in project activities, which are characterized by factors of unpredictability. Management and teams must have the authority to plan and organize work, using their creativity and intellect to deal with risks (Charvat, 2003). AMs use mainly proactive risk management actions, but they can involve reactive action in case of doubt or when the risks become reality. The term risk refers to events rather than more general sources of uncertainty. In projects carried out in rapidly changing environments, where uncertainty is inevitable and traditional risk management is insufficient, it is necessary to adopt roles and techniques oriented less toward planning and more toward flexibility and learning (Petit, 2012).

Autonomy is one of the dimensions of EO that is most evident in the context of AM. Increasing autonomy allows, for example, the team to reduce the time, cost and resources needed to understand the need for changing requirements and to make the necessary changes to projects (Lee \& Xia, 2010). Entrepreneurial culture, self-managed teams and autonomy in decision-making are important for the adoption of AM (Conforto et al., 2014). Proactiveness is also part of the context of decision-making and anticipation. In this sense, it is important that agile teams are composed of individuals with knowledge of their own skills combined with good interpersonal skills and confidence (Dybå \& Dingsøyr, 2008). In the absence of the traditional role of the project manager, who takes on the role of facilitator to direct and coordinate the team's collaborative efforts (Nerur et al., 2005), the proactiveness and autonomy of team members takes on a role active. The focus on interaction, collaboration and action according to each situation is evident, with people being seen as the main drivers of success, which is why the power over daily operations is given to operational personnel, not to project managers (Gustavsson \& Hallin, 2014).

Finally, competitive aggressiveness is also valued in AM, as agile processes take advantage of changes to achieve competitive advantage for the client (Rivas \& Godoy de Souza, 2014). Agile development of software evolves toward agility in project management favoring business competitiveness (Stettina \& Hörz, 2015). The discussion on the dimensions of $\mathrm{EO}$ in the context of AM, motivated by the confirmation of the contribution of $\mathrm{EO}$ in the use of $\mathrm{AM}$, refers to the need for future studies to understand the contribution of each of the dimensions of $\mathrm{EO}$ in the use of $\mathrm{AM}$ in project management in depth.

In terms of practical implications, the results show that if organizations aim to encourage the use of AM and adhere to its guiding values, they must present entrepreneurial behavior patterns, encouraging actions and behaviors related to the dimensions of EO. The development of an entrepreneurial strategy of the organization focused on innovation, on boldness for risk, on proactiveness in the development of projects and activities, on an aggressive attitude toward the market, and on the autonomy of individuals and teams, favors the incorporation of agile values, which are the foundation of agile project management.

\section{Final remarks}

The results of the study show that EO can explain $19.7 \%$ of the use of agile methods in project management. Given that $80.30 \%$ are not explained in this study, the complexity of the context of agile methods is evident, suggesting the development of new studies to better understand agility in the context of projects. In addition, another study may involve the inclusion of moderating or mediating variables of this EO contribution in the use of AM in project management to understand new relationships that may eventually be identified.

A first limitation of this study is the restriction of results to the context studied, to the sample of essentially Brazilian companies operating in the IT segment, with a greater concentration of medium and large-sized companies. Thus, the results found cannot be generalized. However, they can give evidence about its application to companies with characteristics similar to the sample in this study. Another limitation refers to the values 
INMR 18,1

presented for CC of the latent variable IN (0.540), which may represent a bias in the survey's responses. Further work needs to be done to solve this issue.

\section{References}

Alacantara, D., \& Martens, M. L. (2019). Technology roadmapping: a systematic review of the literature focusing on models. Technological Forecasting and Social Change, 138, 127-138. doi: https://doi. org/10.1016/j.techfore.2018.08.014.

Beck, K. Beedle, M. van Bennekum, A. Cockburn, A. Cunningham, W. Fowler, M. . . Thomas, D. (2001). Manifesto for agile software development. Disponível em Retrieved from www.agilemanifesto. org (acesso em 06/02/2020).

Ben-David, A., Gelbard, R., \& Milstein, I. (2012). Supplier ranking by multi-alternative proposal analysis for agile projects. International Journal of Project Management, 30(6), 723-730. doi: https://doi.org/10.1016/j.ijproman.2012.01.002.

Bido, B. S., Godoy, A. S., Araujo, B. F. V. B., \& Louback, J. C. (2010). A articulação entre as aprendizagens individual, grupal e organizacional: Um estudo no ambiente industrial. Ram. Revista de Administração Mackenzie, 11(2), 68-95. doi: https://doi.org/10.1590/S167869712010000200004 .

Byrne, B. M. (2010). Structural equation modeling with AMOS: Basic concepts, applications, and programming, 2nd ed., New York, NY: Routledge.

Carlos, R., Amaral, D., \& Caetano, M. (2018). Framework for continuous agile technology roadmap updating. Innovation \& Management Review, 15(3), 321-336. doi: https://doi.org/10.1108/INMR05-2018-0030.

Charvat, J. (2003). Project management methodologies: Selecting, implementing, and supporting methodologies and processes for projects, John Wiley \& Sons.

Chin, W. W. (2010). How to write up and report PLS analyses. V. E. Vinzi, W. W. Chin, J. Henseler, \& H. Wang, (Eds). Handbook of partial least squares, pp. 655-690. Berlin: Heidelberg. in

Cohen, J. (1988). Statistical power analysis for the behavioral sciences, 2nd ed., Hillsdale, NJ: Erlbaum.

Conforto, E. C., Amaral, D. C., Silva, S. L., Di Felippo, A., \& Kamikawachi, D. S. L. (2016). The agility construct on project management theory. International Journal of Project Management, 34(4), 660-674. doi: https://doi.org/10.1016/j.ijproman.2016.01.007.

Conforto, E. C., Salum, F., Amaral, D. C., Silva, S. L., \& Almeida, L. F. M. (2014). Can agile project management be adopted by industries other than software development? Project Management Journal, 45(3), 21-34. doi: https://doi.org/10.1002/pmj.21410.

Covin, J. G., \& Lumpkin, G. T. (2011). Entrepreneurial orientation theory and research: Reflections on a needed construct. Entrepreneurship Theory and Practice, 35(5), 855-872. doi: https://doi.org/ 10.1111/j.1540-6520.2011.00482.x.

Covin, J. G., \& Slevin, D. P. (1989). Strategic management of small firms in hostile and benign environments. Strategic Management Journal, 10(1), 75-87. doi: https://doi.org/10.1002/ smj.4250100107.

Dybå, T., \& Dingsøyr, T. (2008). Empirical studies of agile software development: A systematic review. Information and Software Technology, 50(9-10), 833-859. doi: https://doi.org/10.1016/j.infsof.2008.01.006.

Faul, F., Erdfelder, E., Buchner, A., \& Lang, A. G. (2009). Statistical power analyses using G* power 3.1: Tests for correlation and regression analyses. Behavior Research Methods, 41(4), 1149-1160. doi: https://doi.org/10.3758/BRM.41.4.1149.

Falk, R. F., \& Miller, N. B. (1992). A primer for soft modeling, Akron, OH: The University of Akron Press.

Floricel, S., Michela, J. L., \& Piperca, S. (2016). Complexity, uncertainty-reduction strategies, and project performance. International Journal of Project Management, 34(7), 1360-1383. doi: https://doi. org/10.1016/j.ijproman.2015.11.007. 
Fornell, C., \& Larcker, D. F. (1981). Evaluating structural equation models with unobserved variables and measurement error. Journal of Marketing Research, 18(1), 39-50. doi: https://doi.org/10.1177/ 002224378101800104.

Entrepreneurial orientation

Freitas, H., Martens, C. D. P., Boissin, J. P., \& Behr, A. (2012). Elementos Para guiar ações visando à orientação empreendedora em organizações de software. Revista de Administração, 47(2), pp. 163-179. doi: https://doi.org/10.5700/rausp1032.

Freitas, H., Oliveira, M., Saccol, A. Z., \& Moscarola, J. (2000). O método de pesquisa survey. Revista de Administração, 35(3), 105-112.

Götz, O., ; Liehr-Gobbers, K., \& Krafft, M. (2010). Evaluation of structural equation models using the partial least squares (PLS) approach. In V. E. Vinzi, W. W. Chin, J. Henseler, \& H. Wang, (Eds). Handbook of partial least squares. Measurement (pp. 691-711). Berlin, Heidelberg: Springer.

Gren, L., Torkar, R., \& Feldt, R. (2017). Group development and group maturity when building agile teams: a qualitative and quantitative investigation at eight large companies. Journal of Systems and Software, 124, 104-119. doi: https://doi.org/10.1016/j.jss.2016.11.024.

Gren, L., Torkar, R., \& Feldt, R. (2015). The prospects of a quantitative measurement of agility: A validation study on an agile maturity model. Journal of Systems and Software, 107, 38-49. doi: https://doi.org/10.1016/j.jss.2015.05.008.

Gustavsson, T. K., \& Hallin, A. (2014). Rethinking dichotomization: a critical perspective on the use of "hard" and "soft" in project management research. International Journal of Project Management, 32(4), 568-577. doi: https://doi.org/10.1016/j.ijproman.2013.10.009.

Hair, J. F., Black, W. C., Babin, B. J., Anderson, R. E., \& Tatham, R. L. (2009). Análise multivariada de dados, 6th ed., Porto Alegre: Bookman.

Hair, J. F., Hult, G. T. M., Ringle, C. M., \& Sarstedt, M. (2014). A primer on partial least squares structural equation modeling (PLS-SEM, Thousand Oaks: Sage Publications, Inc.

Hass, K. B. (2007). The blending of traditional and agile project management. PM World Today, 9(5), 1-8.

Henseler, J., Ringle, C. M., \& Sinkovics, R. R. (2009). The use of partial least squares path modeling in international marketing. Advances in International Marketing, 20, 277-319.

Jarvis, C. B., Mackenzie, S. B., \& Podsakoff, P. M. (2003). A critical review of construct indicators and measurement model misspecification in marketing and consumer research. Journal of Consumer Research, 30(2), 199-218. doi: https://doi.org/10.1086/376806.

Jones, M. V., \& Coviello, N. E. (2005). Internationalisation: Conceptualising an entrepreneurial process of behaviour in time. Journal of International Business Studies, 36(3), 284-303. doi: https://doi.org/10.1057/ palgrave.jibs.8400138.

Kapsali, M. (2011). Systems thinking in innovation project management: A match that works. International Journal of Project Management, 29(4), 396-407. doi: https://doi.org/10.1016/j. ijproman.2011.01.003.

Kuratko, D. F., Morris, M. H., \& Schindehutte, M. (2015). Understanding the dynamics of entrepreneurship through framework approaches. Small Business Economics, 45(1), 1-13. doi: https://doi.org/10.1007/s11187-015-9627-3.

Lee, G., \& Xia, W. (2010). Toward agile: An integrated analysis of quantitative and qualitative field data on software development agility. Mis Quarterly, 34(1), 87-114.

Leppänen, M. (2013). A comparative analysis of agile maturity models. Information systems development (pp. 329-343). New York, NY: Springer.

Li, Y., Yang, M. H., Klein, G., \& Chen, H. G. (2011). The role of team problem solving competency in information system development projects. International Journal of Project Management, 29(7), 911-922. doi: https://doi.org/10.1016/j.ijproman.2010.09.004.

Liu, L. C., \& Horowitz, E. (1989). A formal model for software project management. IEEE Transactions on Software Engineering, 15(10), 1280. 
INMR 18,1

Lumpkin, G. T., \& Dess, G. G. (1996). Clarifying the entrepreneurial orientation construct and linking it to performance. Academy of Management Review, 21(1), 135-172. doi: https://doi.org/10.5465/ amr.1996.9602161568.

Lumpkin, G. T., \& Dess, G. G. (2001). Linking two dimensions of entrepreneurial orientation to firm performance: The moderating role of environment and industry life cycle. Journal of Business Venturing, 16(5), 429-451. doi: https://doi.org/10.1016/S0883-9026(00)00048-3.

Lumpkin, G. T., Cogliser, C. C., \& Schneider, D. R. (2009). Understanding and measuring autonomy: An entrepreneurial orientation perspective. Entrepreneurship Theory and Practice, 33(1), 47-69. doi: https://doi.org/10.1111/j.1540-6520.2008.00280.x.

Martens, C. D. P., Freitas, H. M. R., Boissin, J. P., \& Behr, A. (2011). Elementos da inovatividade no setor software: Estudo exploratório em organizações empreendedoras do Rio Grande Do Sul. RAIRevista de Administração e Inovação, 8(1), 248-279.

Martens, C. D. P., Machado, F. J., Martens, M. L., Silva, F. Q. P. O., \& Freitas, H. M. R. (2018). Linking entrepreneurial orientation to project success. International Journal of Project Management, 36(2), 255-266. doi: https://doi.org/10.1016/j.ijproman.2017.10.005.

Martens, C. D. P., Lacerda, F. M., Belfort, A. C., \& Freitas, H. M. R. D. (2016). Research on entrepreneurial orientation: Current status and future agenda. International Journal of Entrepreneurial Behavior \& Research, 22(4) doi: https://doi.org/10.1108/IJEBR-08-2015-0183.

Meskendahl, S. (2010). The influence of business strategy on project portfolio management and its success - A conceptual framework. International Journal of Project Management, 28(8), 807817. doi: https://doi.org/10.1016/j.ijproman.2010.06.007.

Milašinović, B., \& Bakarčić, T. (2019). A Case Study on Finding Convenient Approach to Practice Agile Methodologies in Software Engineering Courses. Central European Conference on Information and Intelligent Systems (pp. 305-311). Faculty of Organization and Informatics Varazdin.

Mundra, A., Misra, S., \& Dhawale, C. A. (2013). Practical scrum-scrum team: Way to produce successful and quality software. 2013 13th International Conference on Computational Science and Its Applications (pp. 119-123). IEEE.

Nerur, S., Mahapatra, R., \& Mangalaraj, G. (2005). Challenges of migrating to agile methodologies. Communications of the ACM, 48(5), 72-78. doi: https://doi.org/10.1145/1060710.1060712.

Oblog, T., Oblog, K., \& Pratt, M. G. (2010). Dominant logic and entrepreneurial firms' performance in a transition economy. Entrepreneurship Theory and Practice, 34(1), 151-170. doi: https://oi.org/10.1111/ j.1540-6520.2009.00367.x.

Petit, Y. (2012). Project portfolios in dynamic environments: Organizing for uncertainty. International Journal of Project Management, 30(5), 539-553. doi: https://doi.org/10.1016/j.jproman.2011.11.007.

Rasnacis, A., \& Berzisa, S. (2017). Method for adaptation and implementation of agile project management methodology. Procedia Computer Science, 104, 43-50. doi: https:/doi.org/10.1016/j.procs.2017.01.055.

Rauch, A., Wiklund, J., Lumpkin, G. T., \& Frese, M. (2009). Entrepreneurial orientation and business performance: An assessment of past research and suggestions for the future. Entrepreneurship Theory and Practice, 33(3), 761-787. doi: https://doi.org/10.1111/j.1540-6520.2009.00308.x.

Ringle, C. M., Da Silva, D., \& Bido, D. D. S. (2014). Modelagem de equações estruturais com utilização do SmartPLS. REMark. Revista Brasileira de Marketing, 13(2), 54.

Ringle, C. M. Wende, S., \& Becker, J.-M. (2015). SmartPLS 3. Bönningstedt: SmartPLS. Retrieved from http://www.smartpls.com

Rivas, M. A., \& Godoy de Souza, E. (2014). Análise comparativa da utilização do modelo tradicional (waterfall) de desenvolvimento de projetos e o modelo ágil (agile) em fábricas de software. RSC. Revista de Sistemas e Computação, 4(1)

Santos, I. L., \& Marinho, S. V. (2018). Relationship between entrepreneurial orientation, marketing capability and business performance in retail supermarkets in Santa Catarina (Brazil). Innovation \& Management Review, 15(2), 118-136. 
Schwaber, K. (2004). Agile Project Management with Scrum, Redmond: Microsoft Press.

Sheffield, J., \& Lemétayer, J. (2013). Factors associated with the software development agility of successful projects. International Journal of Project Management, 31(3), 459-472. doi: https://doi. org/10.1016/j.ijproman.2012.09.011.

Špundak, M. (2014). Mixed agile/traditional project management methodology - Reality or illusion? Procedia Social and Behavioral Sciences, 119, 939-948. doi: https://doi.org/10.1016/j.sbspro.2014.03.105.

Stettina, C. J., \& Hörz, J. (2015). Agile portfolio management: An empirical perspective on the practice in use. International Joumal of Project Management, 33(1), 140-152. doi: https://doi.org/10.1016/j. ijproman.2014.03.008.

Surendra, N. C., \& Nazir, S. (2018). Agile development: Exploring what practitioners want to know. Journal of Software Engineering and Applications, 11(01), 1-11. doi: https://oi.org/10.4236/jsea.2018.111001.

Tolfo, C., Wazlawick, R. S., Ferreira, M. G. G., \& Forcellini, F. A. (2018). Agile practices and the promotion of entrepreneurial skills in software development. Journal of Software: Evolution and Process, 30(9), $1945 \mathrm{e}$

Vallon, R., da Silva Estacio, B. J., Prikladnicki, R., \& Grechenig, T. (2018). Systematic literature review on agile practices in global software development. Information and Software Technology, 96, 161-180. doi: https://doi.org/10.1016/j.infsof.2017.12.004.

Van Marrewijk, A. (2007). Managing project culture: The case of environ megaproject. International Journal of Project Management, 25(3), 290-299. doi: https://doi.org/10.1016/j.jproman.2006.11.004.

Van Marrewijk, A., Clegg, S. R., Pitsis, T. S., \& Veenswijk, M. (2008). Managing public-private megaprojects: Paradoxes, complexity, and project design. International Journal of Project Management, 26(6), 591-600.

VersionOne, C. (2019). 13th annual state of agile report. Disponível em:Retrieved from https://www.stateofagile. com/\#ufh-i-521251909-13th-annual-state-of-agile-report/473508 (acesso em 01/03/2020).

\section{Further reading}

Iqbal, J., Omar, M., \& Yasin, A. (2019). The impact of agile methodologies and cost management success factors: An empirical study. Baghdad Science Journal, 16(2), 496-504.

Lawrence, K. (2013). Developing leaders in a VUCA environment. UNC Executive Development, 1-15.

Serrador, P., \& Pinto, J. K. (2015). Does agile work? - A quantitative analysis of agile project success. International Journal of Project Management, 33(5), 1040-1051. doi: https://doi.org/10.1016/j. ijproman.2015.01.006.

\section{Corresponding author}

Vanessa Mesquita Blas Garcia can be contacted at: vmbg17@gmail.com

For instructions on how to order reprints of this article, please visit our website: 